\title{
Beginning of a New Era for the Annals of Dentistry University of Malaya (Ann Dent UM)
}

\author{
Zainal Ariff Abdul Rahman
}

Since 1994 Ann Dent UM is publishing scholarly contributions in the broader field of Dentistry.

Likewise the faculty of Dentistry at University of Malay, as the pioneer school of Dentistry in Malaysia, it's official journal has also pioneered the milestone of dental journal publications in the country.

Over the years, the journey for the journal has not been always as smooth as it could have been. Nevertheless 25 years has been a long time to be in existence in the world of scientific peer-reviewed publications.

In view of embracing the challenge to become an indexed journal, the Faculty has agreed to restructure the editorial team to operate the journal's day to day operation independently. Hence, with the new structure and composition of the Editorial team under the leadership of the Executive Editor, Ann Dent UM is expected to have more efficient editorial decision making for high quality publications in the broader field of Dentistry.

The distinguished editorial team is now comprises of highly experienced specialists from both fundamental and clinical Dentistry. Given the secure footing of the journal that started

\footnotetext{
1 Dean, Faculty of Dentistry, University of Malaya

Advisor, Editorial Team, Ann Dent UM

*Correspondence: zainalr@um.edu.my
}

about 25 years ago, Ann Dent UM will need to continue to evolve to ensure full advantage of the rapidly changing landscape of scientific publication and information dissemination.

I sincerely hope that the new editorial team will remain flexible in attending to the rapidly shifting scientific communication landscape, while maintaining and intensifying the high standards of academic.

At the same time the journal will meet the new demands and expectations from both authors and readers, that now mostly depends on how a published paper makes an impact in social media, in the community, as well as in industrial development.

I strongly encourage clinical and fundamental researchers in the broader field of Dentistry and Oral health to submit their novel and enlightening manuscripts to Ann Dent UM and make it a leading journal to educate and support the evolving knowledge in the field.

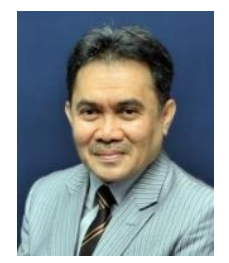

License Information: This work is licensed under a Creative Commons Attribution 